\title{
Effect of bronchofiberscopic lavage with budesonide suspension on refractory mycoplasma pneumoniae pneumonia
}

\author{
Ya $\mathrm{Li}^{1}$, Wei Yang${ }^{2}$, Xin Wu $\mathrm{W}^{3}$, Xiaohua Gou
}

\begin{abstract}
Objectives: To investigate the clinical efficacy of budesonide suspension through bronchofiberscopic lavage in the treatment of refractory mycoplasma pneumoniae pneumonia (RMPP).

Methods: A total of 108 children with refractory mycoplasma pneumoniae pneumonia from June 2018 to October 2020 were randomly divided into two groups: the study group and the control group, with 54 cases in each group. Children in the control group were treated with anti-infective, antitussive, antipyretic routine symptomatic treatment and nebulization of budesonide suspension, while children in the study group were treated with bronchofiberscopic lavage with Budesonide suspension along with standard treatment as in control group. The clinical efficacy, changes in blood gas analysis indexes, levels of inflammatory mediators, time for improvement of clinical symptoms and the incidence of adverse reactions were compared between the two groups.

Results: The efficacy of treatment in the study group was $85.19 \%$, which was higher than $66.67 \%$ in the control group $(\mathrm{P}<0.05)$. The antipyretic time, antitussive time, lung rales disappearance time and length of hospital stay in the study group were shorter than those in the control group $(\mathrm{P}<0.05)$. Moreover, the levels of arterial oxygen partial pressure $\left(\mathrm{PaO}_{2}\right)$ in the study group were higher than those in the control group, while the levels of partial pressure of carbon dioxide $\left(\mathrm{PaCO}_{2}\right)$ and arterial oxygen saturation $\left(\mathrm{SaO}_{2}\right)$ in the study group were lower than those in the control group $(P<0.05)$. The levels of inflammatory mediators interleukin-6 (IL-6), interleukin-4 (IL-4), and interferon- $\gamma$ (IFN- $\gamma$ ) in the study group were lower than those in the control group $(P<0.05)$, and no significant difference was found in the comparison of the incidence of adverse reactions between the two groups $(P>0.05)$.

Conclusions: Budesonide suspension combined with bronchofiberscopic lavage with Budesonide suspension is a safe treatment regimen that can significantly improve the clinical outcome in children with RMPP. With such a combined treatment regimen, the clinical symptoms of children can be ameliorated, the ventilation function can be enhanced, and the level of inflammatory mediators will be reduced.
\end{abstract}

KEYWORDS: budesonide suspension; bronchofiberscopic lavage; refractory pneumonia; mycoplasma pneumonia.

doi: https://doi.org/10.12669/pjms.38.4.4835

How to cite this:

Li Y, Yang W, Wu X, Gou X. Effect of bronchofiberscopic lavage with budesonide suspension on refractory mycoplasma pneumoniae pneumonia. Pak J Med Sci. 2022;38(4):922-927. doi: https://doi.org/10.12669/pjms.38.4.4835

This is an Open Access article distributed under the terms of the Creative Commons Attribution License (http://creativecommons.org/licenses/by/3.0), which permits unrestricted use, distribution, and reproduction in any medium, provided the original work is properly cited.

Note: Ya Li and Xiaohua Gou are both considered as co-first authors.

Correspondence:

Ya Li,

Pulmonary and Critical Care Medicine $2^{\text {nd }}$ Department,

Baoding First Central Hospital,

Baoding 071000, Hebei, China.

Email: ly519369@126.com

* Received for Publication:

* Revision Received:

* Revision Accepted: *
July 28, 2021

December 27, 2021

January 13, 2022

\section{INTRODUCTION}

Mycoplasma pneumoniae pneumonia, as an interstitial pneumonia caused by mycoplasma pneumoniae infection, is one of the most common respiratory infections in clinical practice, with an increasing incidence year by year. ${ }^{1-3}$ Macrolide antibiotics are currently the preferred treatment drugs for refractory mycoplasma pneumoniae 
pneumonia (RMPP). However, with the increase of mycoplasma resistance to macrolide antibiotics, conventional macrolide antibiotics alone have poor efficacy in the treatment of RMPP. ${ }^{4,5}$ Budesonide, a non-halogenated glucocorticoid, can reduce vascular permeability, inhibit secretion of mucus, and relieve edema and spasm. Budesonide which is inhaled after nebulization can spread to the whole lung and is highly effective to local inflammation. ${ }^{6}$ In recent years, with the maturity of bronchoscopy technology, the therapeutic value of alveolar lavage on infected sites has been widely recognized.? Budesonide suspension is touted to have a repair effect on inflammatory airway injury tissues, with little systemic effect and high safety. ${ }^{8}$ Local administration of budesonide after bronchoscopic alveolar lavage may achieve better efficacy. In this study, the clinical efficacy of bronchofiberscopic lavage combined with budesonide suspension in the treatment of RMPP was investigated, and adverse reactions were observed.

\section{METHODS}

A total of 108 children with RMPP from June 2018 to October 2020 were randomly divided into two groups: the study group and the control group, with 54 cases in each group. Among all the children, there were 32 males and 22 females in the study group, aged 1-12 years, with an average of $7.84 \pm 2.16$ years. Their body temperature ranged from $37.5-39.8^{\circ} \mathrm{C}$, with an average temperature of $38.44 \pm 0.73^{\circ} \mathrm{C}$, and the course of disease ranged from $7-14 \mathrm{~d}$, with an average course of $9.69 \pm 1.24 \mathrm{~d}$. In the control group, there were 30 males and 24 females, aged 1-14 years, with an average of $7.95 \pm 2.33$ years. Their body temperature ranged from $37.8-39.7^{\circ} \mathrm{C}$, with an average temperature of $38.37 \pm 0.82^{\circ} \mathrm{C}$, and the course of disease ranged from $8-15 \mathrm{~d}$, with an average course of $9.88 \pm 1.36$. No statistically significant difference was observed in the general information of the two groups $(\mathrm{P}>0.05)$.

RMPP was defined as: (1) sputum culture, serum etiology and lung CT suggested mycoplasma pneumoniae pneumonia in children; (2) a sustained fever for 7 days or more and; (3) increasingly severe cough and infiltrates on chest radiographs despite the administration of appropriate macrolide antibiotics.

Ethical Approval: The study was approved by the Institutional Ethics Committee of Baoding First Central Hospital at March 10, 2021(No.2021.3.10), and written informed consent was obtained from all participants

\section{Inclusion criteria:}

- Children who meet the diagnostic criteria for RMPP by imaging examination and laboratoryrelated instrumental examinations; ${ }^{9}$

- Children aged 1-14 years;

- Children whose family members signed the informed consent and approved by the ethics committee of the hospital.

\section{Exclusion criteria:}

- Children who are allergic to the drugs used in this study;

- Children with hereditary blood diseases and mental diseases;

- Children with pulmonary neoplasms or noninfectious interstitial pulmonary diseases;

- Children with a past history of bronchial asthma, immunodeficiency disease, recurrent respiratory infections, and tuberculosis infectious diseases;

- Children with fungal infection

- Children with severe malnutrition and debilitating physical conditions.

Children in the control group were given conventional treatment, including symptomatic treatment measures such as expectoration, oxygen inhalation, respiratory support, nutritional support, and postural drainage, and were treated with the following drugs for fourteen days according to the sputum culture drug sensitivity test and serum pathogen detection, such as macrolide antibiotic intravenous drip anti-infection, $10 \mathrm{mg} /(\mathrm{kg} \cdot \mathrm{d})$ azithromycin (Northeast Pharmaceutical Group Shenyang No.1 Pharmaceutical Co., Ltd., State Drug Approval No.: H20000426), 80-160 mg/ (kg d) cephalosporin antibiotic - cefotiam hydrochloride (Hainan Quanxing Pharmaceutical Co.,Ltd., State Drug Approval No.: H20113468), or 30-100 mg/ $(\mathrm{kg} \cdot \mathrm{d})$ cefuroxime sodium (Guangdong Jincheng Jinsu Pharmaceutical Co., Ltd., State Drug Approval No.: H20065670) or intravenous infusion of 50-100 $\mathrm{mg} /(\mathrm{kg} \cdot \mathrm{d}$ ) cephalosporin sodium (Hainan Huluwa Pharmaceutical Group Co., Ltd., National Drug Approval: H20064990), and nebulized budesonide suspension (AstraZeneca Pharmaceutical Co., Ltd., State Drug Approval No.: H20140475). All drugs given without sputum examination or any other serological test? Quinolones can be an alternative medication; Mycoplasma is generally resistant to beta Lactam.

For children in the study group, on the basis of the treatment regimen of the control group. The children were fasted for four to six hour before surgery, and were given lidocaine spray anesthesia in nasal 
cavity and pharynx 30 minutes before surgery, and the total amount of medication should be controlled within $5-7 \mathrm{mg} / \mathrm{kg}$. During the operation, the child was supine, one side of the nasal cavity was inhaled with high concentration of oxygen through the nasal catheter. And the front end of the fibrous bronchus was lubricated and slowly entered the other side of the nasal cavity, then bronchoalveolar lavage was performed. The sputum of the affected lung segment and leaf was sucked up. The saline at $37^{\circ} \mathrm{C}$ was infused with a perfusion volume of $5-10 \mathrm{ml}$ for each segment of the bronchus. After the infusion, suction was performed with negative pressure, and the pulmonary bronchus in the infected area was flushed 3-4 times each time, with the total amount of perfusion normal saline not more than $5 \mathrm{ml} / \mathrm{kg}$. Then budesonide suspension was injected into the lesion site. The treatment time of the study group was the same as that of the control group.

\section{Observation Indexes}

Criteria for curative effect: ${ }^{10}$ After $10 \mathrm{~d}$ of treatment, the therapeutic effect was evaluated, and the clinical efficacy was divided into four grades: cured, markedly effective, effective and ineffective. Cured: The children's body temperature returned to normal, lung rales and symptoms disappeared completely, and the lung lesions were $95 \%$ absorbed by X-ray examination.

Markedly effective: The temperature of the children was normal, the pulmonary symptoms and lung rales basically disappeared, and the lung lesions were $90 \%$ absorbed by X-ray examination. Effective: The temperature of the children dropped by more than $1^{\circ} \mathrm{C}$, symptoms were alleviated, lung rales were significantly reduced, lung lesions were $80 \%$ absorbed by X-ray examination, and inflammation absorption and lesion abnormality were effectively improved.

Ineffective: The children's high fever did not retreat, the symptoms worsened, the X-ray review changed by $20 \%$, or even worsened. (2) Blood gas indexes were analyzed before and after treatment, and arterial partial pressure of oxygen $\left(\mathrm{PaO}_{2}\right)$, partial pressure of carbon dioxide (PaCO2) and arterial oxygen saturation $\left(\mathrm{SaO}_{2}\right)$ were measured. (3) Before and after treatment, $3 \mathrm{ml}$ of fasting peripheral venous blood was collected, and anticoagulant blood was collected in an EDTA vacuum. Centrifugation was carried out in a high-speed refrigerated centrifuge at room temperature at 3000r/min for 15 minutes. After serum separation, the levels of interleukin-6 (IL-6), interleukin-4 (IL-4) and interferon $\gamma($ IFN- $\gamma$ ) were detected by double antibody sandwich enzyme-linked immunosorbent assay. (4) The improvement of clinical symptoms and signs in the two groups were counted, including the antipyretic time, antitussive time, lung rales disappearance time and total length of hospital stay. (5) The incidence of adverse reactions in the two groups during treatment was observed.

Statistical Analysis SPSS23.0 was used for data statistics and analysis. Measurement data were expressed by mean and standard deviation and analyzed by $\mathrm{t}$ test; Count data were expressed by frequency and rate and analyzed by chi-square test. $\mathrm{P}<0.05$ indicates a statistically significant difference.

\section{RESULTS}

The effective rate of treatment for children in the study group was $85.19 \%$, which was higher than $66.67 \%$ in the control group $(\mathrm{P}<0.05)$. Table-I. The level of $\mathrm{PaO}_{2}$ in the two groups was higher than that before treatment, and that in the study group was higher than that in the control group, with a statistically significant difference $(\mathrm{P}<0.05)$. The levels of $\mathrm{PaCO}_{2}$ and $\mathrm{SaO}_{2}$ in the two groups were lower than before treatment, and that in the study group was higher than that in the control group, with a statistically significant difference $(\mathrm{P}<0.05)$. Table-II.

The levels of IL-6, IL-4, and IFN- $\gamma$ in the two groups after treatment were lower than those before treatment, and that in the study group was lower than that in the control group, with a statistically significant difference $(\mathrm{P}<0.05)$. Table-III. The antipyretic time, antitussive time, lung rales disappearance

Table-I: Comparison of clinical efficacy of children [n (\%)].

\begin{tabular}{lcccccc}
\hline Group & $n$ & Cured & Markedly effective & Effective & Ineffective & Effective rate ( $n, \%)$ \\
\hline Study group & 54 & 21 & 17 & 8 & 8 & $46(85.19)$ \\
Control group & 54 & 13 & 11 & 12 & 18 & $36(66.67)$ \\
$X^{2}$ & & & & & & 5.066 \\
P & & & & & & 0.024 \\
\hline
\end{tabular}


Table-II: Comparison of blood gas index levels between the two groups $(\bar{X} \pm \mathrm{s})$.

\begin{tabular}{lcccccc}
\hline & \multicolumn{2}{c}{$\mathrm{PaO}_{2}(\mathrm{mmHg})$} & \multicolumn{2}{c}{$\mathrm{PaCO}_{2}(\mathrm{mmHg})$} & \multicolumn{2}{c}{$\mathrm{SaO}_{2}(\%)$} \\
\hline Group & $\begin{array}{c}\text { Before } \\
\text { treatment }\end{array}$ & $\begin{array}{c}\text { After } \\
\text { treatment }\end{array}$ & $\begin{array}{c}\text { Before } \\
\text { treatment }\end{array}$ & $\begin{array}{c}\text { After } \\
\text { treatment }\end{array}$ & $\begin{array}{c}\text { Before } \\
\text { treatment }\end{array}$ & $\begin{array}{c}\text { After } \\
\text { treatment }\end{array}$ \\
\hline Study group $(\mathrm{n}=54)$ & $48.33 \pm 3.69$ & $81.35 \pm 7.93$ & $63.25 \pm 6.36$ & $43.54 \pm 5.93$ & $53.73 \pm 6.78$ & $41.44 \pm 5.21$ \\
Control group $(\mathrm{n}=54)$ & $48.69 \pm 4.25$ & $67.36 \pm 6.91$ & $64.07 \pm 5.88$ & $52.08 \pm 6.22$ & $53.95 \pm 6.24$ & $48.83 \pm 4.36$ \\
$t$ & 0.470 & 9.774 & 0.696 & 7.302 & 0.175 & 7.994 \\
$P$ & 0.639 & $<0.001$ & 0.488 & $<0.001$ & 0.861 & $<0.001$ \\
\hline
\end{tabular}

Table-III: Changes in the levels of IL-6, IL-4 and IFN- $\gamma$ between the two groups $(\bar{X} \pm \mathrm{s})$.

\begin{tabular}{lcccccc}
\hline & \multicolumn{2}{c}{$I \mathrm{~L}-6(\mathrm{pg} / \mathrm{ml})$} & \multicolumn{2}{c}{$I \mathrm{~L}-4(\mathrm{pg} / \mathrm{ml})$} & \multicolumn{2}{c}{$I F N-\gamma(\mathrm{pg} / \mathrm{ml})$} \\
\hline Group & $\begin{array}{c}\text { Before } \\
\text { treatment }\end{array}$ & $\begin{array}{c}\text { After } \\
\text { treatment }\end{array}$ & $\begin{array}{c}\text { Before } \\
\text { treatment }\end{array}$ & $\begin{array}{c}\text { After } \\
\text { treatment }\end{array}$ & $\begin{array}{c}\text { Before } \\
\text { treatment }\end{array}$ & $\begin{array}{c}\text { After } \\
\text { treatment }\end{array}$ \\
\hline Study group $(\mathrm{n}=54)$ & $39.57 \pm 5.73$ & $12.35 \pm 2.03$ & $102.96 \pm 18.54$ & $55.21 \pm 10.02$ & $192.98 \pm 17.25$ & $110.21 \pm 15.32$ \\
Control group $(\mathrm{n}=54)$ & $40.06 \pm 5.86$ & $19.78 \pm 1.96$ & $103.87 \pm 19.25$ & $79.86 \pm 11.05$ & $193.65 \pm 13.84$ & $149.76 \pm 11.02$ \\
$t$ & 0.439 & 19.349 & 0.250 & 12.144 & 0.223 & 15.400 \\
$P$ & 0.661 & $<0.001$ & 0.803 & $<0.001$ & 0.824 & $<0.001$ \\
\hline
\end{tabular}

time and length of hospital stay in the study group were all shorter than those in the control group, with statistically significant differences $(\mathrm{P}<0.05)$. Table-IV. No statistically significant difference was observed in the incidence of adverse reactions between the two groups $(\mathrm{P}>0.05)$. Table- $\mathrm{V}$.

\section{DISCUSSION}

In recent years, the number of refractory or severe cases of mycoplasma pneumoniae pneumonia has increased gradually, with the clinical characteristics of rapid onset, fast progress and relatively

Table-IV: Improvement time of clinical symptoms and signs in the two groups $(\bar{X} \pm \mathrm{s}, \mathrm{d})$.

\begin{tabular}{lcccc}
\hline Group & $\begin{array}{c}\text { Antipyretic } \\
\text { time }\end{array}$ & $\begin{array}{c}\text { Antitussive } \\
\text { time }\end{array}$ & $\begin{array}{c}\text { Lung rales } \\
\text { disappearance time }\end{array}$ & $\begin{array}{c}\text { Length of hospital } \\
\text { stay }\end{array}$ \\
\hline study group $(\mathrm{n}=54)$ & $2.59 \pm 0.58$ & $5.63 \pm 2.07$ & $4.75 \pm 1.52$ & $7.98 \pm 2.26$ \\
Control group $(\mathrm{n}=54)$ & $3.47 \pm 0.68$ & $7.54 \pm 2.38$ & $6.25 \pm 1.57$ & $9.83 \pm 3.45$ \\
$t$ & 7.235 & 4.450 & 5.044 & 3.296 \\
$P$ & $<0.001$ & $<0.001$ & $<0.001$ & 0.001 \\
\hline
\end{tabular}

Table-V: Occurrence of adverse reactions in the two groups during treatment.

\begin{tabular}{lccccc}
\hline Group & $\begin{array}{c}\text { Sinus } \\
\text { Tachycardia }\end{array}$ & $\begin{array}{c}\text { Decreased blood } \\
\text { Oxygen Saturation }\end{array}$ & Vomiting & $\begin{array}{c}\text { Gastrointestinal } \\
\text { Reaction }\end{array}$ & $\begin{array}{c}\text { Total Incidence } \\
n(\%)\end{array}$ \\
\hline Study group $(\mathrm{n}=54)$ & 2 & 1 & 1 & 1 & $5(9.26)$ \\
Control group $(\mathrm{n}=54)$ & 1 & 0 & 2 & 1 & $4(7.41)$ \\
$X^{2}$ & & & & & 0.121 \\
$P$ & & & & & 0.728 \\
\hline
\end{tabular}


migratory courses. Its clinical symptoms range from persistent high fever and cough to reduced breathing sounds with or without rales, and its pulmonary imaging is manifested as large-scale high-density consolidation. ${ }^{11-13}$

Antibiotic anti-infective therapy is the preferred routine treatment for mycoplasma infection. However, strain resistance has been enhanced owing to the massive use of antibiotics at the present stage, resulting in the failure of conventional anti-infective treatments to achieve the desired effect, and the slow recovery of clinical symptoms in children. ${ }^{14-16}$ Budesonide suspension is a glucocorticoid with potent topical anti-inflammatory effects that can enhance the stability of the lysosomal membrane of endothelial cells and smooth muscle cells, inhibit immune response and reduce antibody synthesis. In this way, the release of allergic active mediators such as histamine can be reduced, the activity can be inhibited, the enzymatic process triggered by the binding of antigen and antibody can be reduced, and the synthesis and release of broncho-constrictive substances can be inhibited, thereby reducing the contraction response of smooth muscles, diminishing the leakage of capillaries, exerting a strong local anti-inflammatory effect, inhibiting the hyperresponsiveness of the airway, reducing the secretion of glands, relieving symptoms, and repairing damaged airways. ${ }^{17-19}$ Bronchofiberscopy and alveolar lavage are non-invasive methods developed in recent years. With a soft texture, small lumen and strong light conduction ability, the bronchofiberscope can be easily penetrated into the airway of children, so as to facilitate the observation of the trachea or the opening of the left and right lobes of bronchus and the mucosa. Single or multiple alveolar lavage by bronchoalveolar lavage (BAL) can effectively remove inflammatory secretions of the respiratory tract in children. In combination with antibiotic drugs, mucosal edema in children can be significantly reduced, sputum dissolution can be promoted, and topical anti-inflammatory effect can be intensified, so as to ameliorate clinical symptoms of children. ${ }^{20}$

In this study, budesonide suspension combined with bronchofiberscopic lavage significantly improved the clinical efficacy of RMPP. Studies have shown that the use of intratracheal corticosteroids can not only recruit the lungs, but also alleviate pulmonary inflammation in severe respiratory distress syndrome, which provides support for our study. ${ }^{21}$ Marraro et al. found that children with bronchoalveolar lavage could improve oxygenation index and Pao2/Fio2 more quickly than those with bronchial atomization inhalation under the same medication. ${ }^{22}$ In this study, the levels of $\mathrm{PaO} 2$ in the study group were higher than those in the control group, and the levels of $\mathrm{PaCO} 2$ and $\mathrm{SaO} 2$ were lower than those in the control group, which was consistent with the results of the study. This is mainly related to the fact that bronchofiberscopic lavage can basically remove inflammatory secretions in the trachea of children and relieve airway obstruction. The children treated with budesonide suspension combined with bronchofiberscopic lavage had significantly shorter antipyretic time, antitussive time, lung rales disappearance time and length of hospital stay than those treated with conventional treatment, and their conditions were effectively controlled and clinical symptoms were significantly improved, which was supported by the study results of Tan et al. ${ }^{23}$ There was no significant difference in the incidence of adverse reactions between the two groups during treatment, indicating the high safety of budesonide suspension combined with bronchofiberscopic lavage.

It has been shown in studies ${ }^{24}$ that the expressions of inflammatory factors such as IL-6, IL-4 and IFN- $\gamma$ in serum of children with RMPP were up-regulated, lymphocytes in infected sites were reduced, neutrophils were increased, and local reactions were aggravated. IL- 4 can activate the synthesis of immune proteins, leading to wheezing attacks. IL-6 is a multifunctional cytokine, which has a close bearing on the immune response and the regulation and defense function of the hematopoietic system. It is positively correlated with the severity of infection and inflammation, and is involved in the process of pneumonia infection. IFN- $\gamma$ is mainly produced by Th1 cells and is involved in regulating the immune function of the body after infection, and can mediate the production of other inflammatory mediators. ${ }^{25}$ Budesonide suspension combined with bronchofiberscopic lavage has been touted for various benefits, such as blocking the release of inflammatory mediators and cytokines, significantly reducing serum IL-6, IL-4, and IFN- $\gamma$ levels in children with RMPP, diminishing airway inflammation caused by abnormal immune responses, and improving respiratory symptoms in children.

Limitations of the study: There are still some shortcomings in this study. First of all, the number of subjects included in this study is limited, so the conclusions drawn may not be very convincing. In addition, we should have set up a control group of conventional treatment combined with bronchofib- 
erscopic lavage with normal saline alone to make the findings more definitive and convincing.

\section{CONCLUSION}

Budesonide suspension combined with bronchofiberscopic lavage is a safe treatment regimen that can significantly improve the clinical efficacy of children with RMPP. With such a combined treatment regimen, the clinical symptoms of children can be ameliorated, the ventilation function can be enhanced, and the level of inflammatory mediators will be reduced.

\section{Source of funding: None \\ Conflicts of interest: None}

\section{REFERENCES}

1. Lee E, Young Lee Y. Risk factors for the development of post-infectious bronchiolitis obliterans after Mycoplasma pneumoniae pneumonia in the era of increasing macrolide resistance. Respir Med. 2020;175:106209. doi: 10.1016/j.rmed.2020.106209

2. Wang Z, Yang L, Ye J, Wang Y, Liu Y. Monocyte subsets study in children with Mycoplasma pneumoniae pneumonia. Immunol Res. 2019;67(4-5):373-381. doi: 10.1007/s12026-019-09096-6

3. Lan Y, Li S, Yang D, Zhou J, Wang Y, Wang J, et al. Clinical characteristics of Kawasaki disease complicated with Mycoplasma pneumoniae pneumonia: A retrospective study. Medicine (Baltimore). 2020;99(19):e19987. doi: 10.1097/MD.0000000000019987

4. Qiu JL, Huang L, Shao MY, Chai YN, Zhang HJ, Li XF, et al. Efficacy and safety of azithromycin combined with glucocorticoid on refractory Mycoplasma pneumoniae pneumonia in children: A PRISMAcompliant systematic review and meta-analysis. Medicine (Baltimore). 2020;99(22):e20121. doi: 10.1097/MD.0000000000020121

5. Wang L, Wang W, Sun JM, Ni SW, Ding JL, Zhu YL, et al. Efficacy of fiberoptic bronchoscopy and bronchoalveolar lavage in childhood-onset, complicated plastic bronchitis. Pediatr Pulmonol. 2020;55(11):3088-3095. doi: 10.1002/ppul.25016

6. Li B, Han S, Liu F, Kang L, Xv C. Budesonide Nebulization in the Treatment of Neonatal Ventilator Associated Pneumonia. Pak J Med Sci. 2017;33(4):997-1001. doi: 10.12669/pjms.334.12907

7. Wang LP, Chen SP, Huang YY, Qin FF, Ou W, Liu HD, et al. Application of flexible bronchoscopy in children with respiratory diseases. Zhongguo Dang Dai Er Ke Za Zhi. 2017;19(11):1174-1179. doi: 10.7499/j.issn.1008-8830.2017.11.010

8. Israel S, Kumar A, DeAngelis K, Aurivillius M, Dorinsky P, Roche $\mathrm{N}$, et al. Pulmonary deposition of budesonide/glycopyrronium/ formoterol fumarate dihydrate metered dose inhaler formulated using co-suspension delivery technology in healthy male subjects. Eur J Pharm Sci. 2020;153:105472. doi: 10.1016/j.ejps.2020.105472

9. Harris M, Clark J, Coote N, Fletcher P, Harnden A, McKean M, et al. British Thoracic Society guidelines for the management of community acquired pneumonia in children: update 2011. Thorax. 2011;66(Suppl 2):ii1-23. doi: 10.1136/thoraxjnl-2011-200598

10. Miyashita N, Narita M, Tanaka T, Akaike H, Teranishi H, Oishi T, et al. Histological findings in severe Mycoplasma pneumoniae pneumonia. J Med Microbiol. 2017;66(5):690-692. doi: 10.1099/jmm.0.000501

11. Li G, Fan L, Wang Y, Huang L, Wang M, Zhu C, et al. High co-expression of TNF- $a$ and CARDS toxin is a good predictor for refractory Mycoplasma pneumoniae pneumonia. Mol Med. 2019;25(1):38. doi: 10.1186/s10020-019-0105-2

12. Alishlash AS, Atkinson TP, Schlappi C, Leal SM Jr, Waites KB, Xiao L. Mycoplasma pneumoniae Carriage With De Novo Macrolide-Resistance and Breakthrough Pneumonia. Pediatrics. 2019;144(4):e20191642. doi: 10.1542/peds.2019-1642

13. Li HN, Zhao X, Zha YJ, Du F, Liu J, Sun L. miR-146a-5p suppresses ATP-binding cassette subfamily $G$ member 1 dysregulation in patients with refractory Mycoplasma pneumoniae via interleukin 1 receptor-associated kinase 1 downregulation. Int J Mol Med. 2019;44(6):2003-2014. doi: 10.3892/ijmm.2019.4380
14. YYan C, Xue G, Zhao H, Feng Y, Li S, Cui J, et al. Molecular and clinical characteristics of severe Mycoplasma pneumoniae pneumonia in children. Pediatr Pulmonol. 2019;54(7):1012-1021. doi:10.1002/ ppul.24327

15. Tamiya S, Yoshikawa E, Ogura M, Kuroda E, Suzuki K, Yoshioka Y. Vaccination using inactivated Mycoplasma pneumoniae induces detrimental infiltration of neutrophils after subsequent infection in mice. Vaccine. 2020;38(32):4979-4987. doi: 10.1016/j.vaccine.2020.05.074

16. Gise R, Elhusseiny AM, Scelfo C, Mantagos IS. Mycoplasma Pneumoniae-Induced Rash and Mucositis: A Longitudinal Perspective and Proposed Management Criteria. Am J Ophthalmol. 2020;219:351-356. doi: $10.1016 /$ j.ajo.2020.06.010

17. Rokkas T, Niv Y, Malfertheiner P. A Network Meta-Analysis of Randomized Controlled Trials on the Treatment of Eosinophilic Esophagitis in Adults and Children. J Clin Gastroenterol. 2021;55(5):400-410. doi: 10.1097/MCG.0000000000001356

18. Dorinsky P, DePetrillo P, DeAngelis K, Trivedi R, Darken P, Gillen M. Relative Bioavailability of Budesonide/Glycopyrrolate/ Formoterol Fumarate Metered Dose Inhaler Administered With and Without a Spacer: Results of a Phase I, Randomized, Crossover Trial in Healthy Adults. Clin Ther. 2020;42(4):634-648. doi: 10.1016/j. clinthera.2020.02.012

19. Vizarraga D, Torres-Puig S, Aparicio D, Pich OQ. The Sialoglycan Binding Adhesins of Mycoplasma genitalium and Mycoplasma pneumoniae. Trends Microbiol. 2021;29(6):477-481. doi: 10.1016/j. tim.2021.01.011

20. Venge P, Eriksson S, Pauksen K. Blood biomarker algorithms for the diagnosis of mycoplasma pneumoniae respiratory infections. J Immunol Methods. 2021;489:112908. doi: 10.1016/j.jim.2020.112908

21. Yang CF, Jeng MJ, Soong WJ, Lee YS, Tsao PC, Tang RB. Acute pathophysiological effects of intratracheal instillation of budesonide and exogenous surfactant in a neonatal surfactant-depleted piglet model. Pediatr Neonatol. 2010;51(4):219-226. doi: 10.1016/S18759572(10)60042-3

22. Marraro GA, Luchetti M, Spada C, Galassini E, Giossi M, Piero AM. Selective medicated (normal saline and exogenous surfactant) bronchoalveolar lavage in severe aspiration syndrome in children. Pediatr Crit Care Med. 2007;8(5):476-81. doi: 10.1097/01. PCC.0000282158.09783.7C

23. Tan XZ, Wu SG, Zhang JH, Li XF, Gao PM, Wang Y. Clinical efficacy of porcine pulmonary surfactant combined with budesonide suspension intratracheal instillation in the treatment of neonatal meconium aspiration syndrome. Zhongguo Dang Dai Er Ke Za Zhi. 2016;18(12):1237-1241. doi: 10.7499/j.issn.1008-8830.2016.12.008

24. Chu C, Lei X, Li Y, Luo Y, Ding Y, Zhou W, et al. High expression of miR-222-3p in children with Mycoplasma pneumoniae pneumonia. Ital J Pediatr. 2019;45(1):163. doi: 10.1186/s13052-019-0750-7

25. Su S, Li C, Zhao Y, Yu L, Wang Y, Wang Y, et al. Outbreak of KPC-2-Producing Klebsiella pneumoniae ST76 Isolates in an Intensive Care Unit and Neurosurgery Unit. Microb Drug Resist. 2020;26(9):1009-1018. doi: 10.1089/mdr.2019.0363

Authors' Contributions: YL \& XG: Designed this study and prepared this manuscript, and are responsible and accountable for the accuracy or integrity of the work. WY: Collected and analyzed clinical data. XW: Significantly revised this manuscript.

\section{Authors:}

1. $\mathrm{Ya} \mathrm{Li}$,

Pulmonary and Critical Care Medicine $2^{\text {nd }}$ Department,

2. Wei Yang,

Pulmonary and Critical Care Medicine $2^{\text {nd }}$ Department,

3. Xin $\mathrm{Wu}$

Department of Public Health Section,

4. Xiaohua Gou

Pulmonary and Critical Care Medicine $2^{\text {nd }}$ Department,

1-4: Baoding First Central Hospital,

Baoding071000, Hebei, China. 